\title{
Survival properties of third-generation silicone gel breast implants
}

\author{
Walter Peters PhD MD FRCSC ${ }^{1}$, Stanley Lugowski PhD ${ }^{2}$
}

W Peters, S Lugowski. Survival properties of thirdgeneration silicone gel breast implants. Can J Plast Surg 2002;10(3):109-112.

From 1992 through 2001, 100 third-generation silicone gel breast implants were removed from 50 women who had undergone cosmetic breast augmentation. The main reasons for explantation were: ptosis in 16 patients (32\%); to further increase implant size in 15 patients $(30 \%)$; suspected silicone-related health problems in 11 patients $(22 \%)$; medical disease in five patients $(10 \%)$; and breast firmness and pain in three patients (6\%). Of the 100 thirdgeneration gel implants, 42 were manufactured by McGhan Medical, 38 by Surgitek, 10 by Cox-Uphoff and 10 by Dow Corning. The $42 \mathrm{McGhan}$ implants had been in place for two to 15 years (mean 8.8 years), the 10 Cox-Uphoff implants for seven to 14 years (mean 9.4 years), and the 10 Dow Corning implants for five to 12 years (mean 8.1 years). All the McGhan, CoxUphoff and Dow Corning implants were clinically intact at explantation. By contrast, of the 38 Surgitek third-generation implants, which had been in place for three to 13 years (mean 7.9 years), only 28 were intact. Ten (26\%) had already disrupted. A comparison of Kaplan-Meier survival curves indicated that the 62 third-generation gel implants manufactured by McGhan, CoxUphoff and Dow Corning were much more durable than 271 previously explanted second-generation gel implants. By contrast, the 38 third-generation Surgitek gel implants were less durable than the 271 second-generation implants.

Key Words: Breast implants; Rupture; Survival

\section{Les propriétés de survie des implants mammaire en gel de silicone de troisième génération}

Entre 1992 et 2001, 100 implants mammaires en gel de silicone de troisième génération ont été excisés chez 50 femmes ayant subi une augmentation mammaire esthétique. Les principales raisons de ces exérèses sont une ptose chez 16 patientes (32\%), un désir d'augmentation mammaire plus prononcée chez 15 patientes (30\%), des troubles de santé présumément reliés à la silicone chez 11 patientes (22\%), une maladie chez cinq patientes $(10 \%)$ et une douleur et une fermeté des seins chez trois patientes $(6 \%)$. Sur les 100 implants en gel de troisième génération, 42 avaient été fabriqués par McGhan Medical, 38 par Surgitek, 10 par CoxUphoff et 10 par Dow Corning. Les 42 implants de McGhan étaient en place depuis deux à 15 ans (moyenne de 8,8 ans), les 10 de Cox-Uphoff, depuis sept à 14 ans (moyenne de 9,4 ans) et les 10 de Dow Corning, depuis cinq à 12 ans (moyenne de 8,1 ans). Tous ces implants étaient cliniquement intacts à l'exérèse. Par contre, sur les 38 implants de troisième génération de Surgitek, en place depuis trois à 13 ans (moyenne de 7,9 ans), seulement 28 étaient intacts. Dix (26\%) avaient déjà coulé. D’après une comparaison à l'aide des courbes de survie de Kaplan-Meier, les 62 implants en gel de troisième génération fabriqués par McGhan, CoxUphoff et Dow Corning étaient beaucoup plus durables que les 271 de deuxième génération enlevés antérieurement. Par contre, les 38 implants en gel de troisième génération de Surgitek étaient moins durables que les 271 de deuxième génération.

${ }^{1}$ Division of Plastic Surgery and ${ }^{2}$ Centre for Biomaterials, University of Toronto, Toronto, Ontario

Correspondence: Dr Walter Peters, Suite 802, 600 Sherbourne Street, Toronto, Ontario M4X 1W4. Telephone 416-926-7790, fax 416-926-4997, e-mail walter.peters@utoronto.ca 
$\mathrm{T}^{\mathrm{h}}$ here are three main generations of silicone gel breast implants (1-4). The first-generation implants were made from approximately 1963 to 1972 . They were composed of a thick, firm gel and a thick elastomeric shell. They had woven Dacron (DuPont, USA) patches on their posterior surfaces. These implants have proven to be much more durable than second-generation implants (1,2,4-6). Since 1981, we have explanted more than 600 silicone gel implants, many from women who were having symptoms either local breast symptoms or other symptoms that were anticipated to be related to their implants. Of those implants, 28 were first-generation Dow Corning (USA) prostheses $(2,4,6,7)$. They were explanted after 14 to 28 years in situ (mean 20.8 years). Only one of these implants was ruptured; all others were clinically intact. Thus, in our study, 27 of 28 of the first-generation implants were clinically intact after a mean time of 20.8 years in situ. Not infrequently, firstgeneration implants can rupture during the explantation process. This disruption usually occurs at the attachment site of the Dacron patch. However, this is a mechanical disruption that is induced by the explantation procedure. It does not represent a clinical failure of the implant.

Many women with first-generation implants developed capsular contracture with very firm breasts. In an attempt to overcome this problem and to produce softer breasts, manufacturers developed 'softer' (second-generation) implants (4) with thin, soft or 'responsive' gel and a thin elastomeric wall $(0.13 \mathrm{~mm}$ to $0.20 \mathrm{~mm})$. Heyer-Schulte (USA) and Medical Engineering Corporation (USA) (which later became Surgitek [USA]) introduced their second-generation products in the United States in 1972. Dow Corning introduced a comparable product in the United States in 1975. These products were not released in Canada until four to seven years later (4). They were manufactured until the mid-1980s.

Several studies have shown that second-generation implants are much less durable than their first-generation counterparts (2-4,8). In addition, studies have demonstrated that the survival curves for these implants are different for each manufacturer (8-10). From 1992 through 2001, we

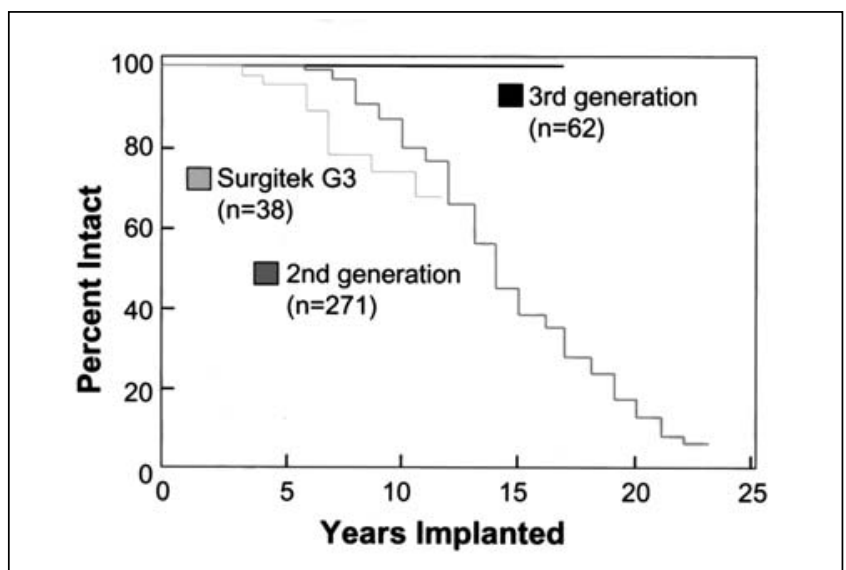

Figure 1) Kaplan-Meier survival curves for 271 second-generation silicone gel implants, 62 third-generation implants manufactured by McGhan (USA), Cox-Uphoff (USA) and Dow Corning (USA), and 38 Surgitek (USA) third-generation gel implants explanted a total of 271 second-generation gel implants with identifiable manufacturers (2,4,6-7). At explantation, $74 \%$ of the implants had ruptured. The Kaplan-Meier survival curve for these implants is shown in Figure 1.

As the failure properties of second-generation implants became apparent, manufacturers addressed this problem by developing third-generation implants (4). These had a stronger and thicker $(0.50 \mathrm{~mm})$ shell (high performance elastomer), which also had a 'barrier layer' to reduce silicone diffusion. McGhan (USA) released its first thirdgeneration implant, the Intrashiel, in 1979, at the American Society for Aesthetic Plastic Surgery annual meeting in Toronto, Ontario. It had a diphenyl barrier layer of proprietary composition. Other companies followed with similar implants. Dow Corning followed with a Silastic II implant that had a 5 to $10 \mathrm{~mm}$ fluorosilicone layer on the inner surface of the shell. The corresponding Surgitek implant (Strong Cohesive Low-Bleed [SCL]) had a diphenyl barrier layer that was incorporated into the wall of the shell. The introduction of third-generation implants was geographically dependent. The Silastic II implant was introduced in the United States in 1981 and in Canada in 1984. The Surgitek SCL implant was introduced in the United States in 1986 and in Canada in 1988.

Earlier studies suggested that third-generation implants were more durable than second-generation implants $(2-4,6)$. However, the numbers of third-generation implants in these studies were small. A larger number of third-generation implants have now been explanted, providing a population for more extensive analysis.

\section{MATERIALS AND METHODS}

The present retrospective study was designed to analyze the failure properties of 100 third-generation silicone gel breast implants that were explanted consecutively from 50 patients from 1992 (the year of the moratorium) through 2001. All 100 implants had been inserted for the purpose of bilateral cosmetic breast augmentation. Patients were selfreferred or were referred by other plastic surgeons or physicians. More than $70 \%$ of the implants had originally been inserted by other plastic surgeons.

The main reasons for explantation are shown in Table 1. Sixteen of the 50 patients $(32 \%)$ requested explantation

\begin{tabular}{|c|c|c|}
\hline Number & Percentage & Main reason for explantation \\
\hline 16 & 32 & Ptosis \\
\hline 15 & 30 & To further increase implant size \\
\hline 11 & 22 & Suspected silicone-related health problems \\
\hline 5 & 10 & Medical disease \\
\hline 3 & 6 & Breast firmness and pain \\
\hline
\end{tabular}


because their nipples had become ptotic over the years, usually after they delivered children and breast fed. Fifteen women $(30 \%)$ requested explantation so that larger implants could be inserted to further increase their breast size. Most of these patients presented later in the study (1998 to 2001). Eleven patients (22\%) requested explantation because of suspected silicone-related health problems. These patients generally presented in the first few years of this study (1992 to 1995). Five of the patients (10\%) requested removal because they had a medical disease that they felt could be associated with their implants. Of these patients, two had fibromyalgia, one had chronic fatigue syndrome, one had rheumatoid arthritis, and one had a renal syndrome with an immunoglobulin A deficiency. Only three patients $(6 \%)$ requested removal because of breast firmness and pain.

All explantations were performed by the same surgeon under direct vision, usually through an inframammary incision. Most patients had existing inframammary scars that were used for explantation. For patients who initially had periareola incisions, these same incisions were usually used for explantation. In most cases, the capsules were not removed unless the patient specifically requested that they be. None of the patients demonstrated capsular calcification.

In this study, failure or disruption of an implant ranged from a small hole in the implant to a frank tear in the implant shell. Of the 100 third-generation gel implants, 42 were McGhan implants, 38 were Surgitek, 10 were CoxUphoff, and 10 were Dow Corning. The 42 McGhan implants had been in place for two to 15 years (mean 8.8 years), the 10 Cox-Uphoff implants for seven to 14 years (mean 9.4 years), and the eight Dow Corning implants for five to 12 years (mean 8.1 years). All the McGhan, Cox-Uphoff and Dow Corning implants were clinically intact at explantation. None were leaking or ruptured. The Kaplan-Meier survival curve for these 62 thirdgeneration implants is shown in Figure 1. In this study, the overall differences among second- and third-generation implants were assessed using the longrank test. Early differences were analyzed by using the Wilcoxon test, and the $-2 \mathrm{Log}$ (longrank) test was used to analyze differences in later years. All three tests had a $\mathrm{P}<0.001$.

By contrast, of the 38 explanted Surgitek third-generation implants, which had been in place for three to 13 years (mean 7.9 years), only 28 were intact. Ten of those implants (26\%) had already failed by leaking or rupturing. It is interesting that those third-generation Surgitek implants were less durable than the third-generation implants of other manufacturers, and that they were even less durable than the 271 previously explanted second-generation implants (Figure 1).

\section{DISCUSSION}

The main reasons for explantation in the present study were much different from those of an earlier explantation outcome study from our laboratories, which was completed in 1996 (6). In that study of 100 women, the main reason for explantation, which was reported in $76 \%$ of patients, was suspected silicone-related health problems. In the present study, this reason was given by only $22 \%$ of patients, and most of these women presented during the early years of the study (1992 to 1996). The main reason for these differences is likely that many reports have been published, particularly during the past few years, indicating that there is no causal relationship between silicone gel breast implants and medical disease $(10,11)$.

This study serves to emphasize the differences in survival properties among second- and third-generation silicone gel breast implants. In addition, it demonstrates the differences in survival properties among different manufacturers within a particular generation. The 62 third-generation silicone gel breast implants manufactured by McGhan, Cox-Uphoff and Dow Corning were much more durable than earlier secondgeneration implants (Figure 1). All 62 implants in this group proved to be intact after a mean time of 8.1 to 9.4 years (range two to 15 years) in situ. By contrast, previous studies have shown that, after a similar time in situ, $20 \%$ to $50 \%$ of second-generation implants had already ruptured $(3,7,10)$.

The 38 third-generation Surgitek silicone gel implants proved to be less durable than the 62 third-generation implants made by other manufacturers (Figure 1). In fact, those Surgitek implants were less durable than even the previously explanted 271 second-generation implants (Figure 1). After 12 years in situ, only 28 of 38 of those implants were intact (Figure 1). Ten (26\%) of those implants had already failed. It should be pointed out that among second-generation gel implants, Surgitek was also shown to produce products that were the least durable of all manufacturers $(8,10)$.

The present study indicates that the third-generation manufacturing changes introduced by McGhan, CoxUphoff and Dow Corning appear to have been effective in reducing the prevalence of disruption of implants during the currently-evaluated study period. These changes included a thicker and stronger elastomeric shell, a more cohesive gel and a barrier layer to the diffusion of silicone oil. It is also significant that none of the implants in this study demonstrated capsular calcification or extracapsular extravasation of gel into breast tissue. Capsular calcification has been demonstrated in all first-generation and many second-generation implants $(6,7,10,12)$. Extravasation has been demonstrated in only second-generation gel implants, in which the gel is much less viscous than that of third-generation implants $(6,10)$. It is anticipated that the recent introduction of the new 'Cohesive Gel' implants (Mentor Medical, USA; McGhan Medical; Kilbride Industrial Estate, Ireland), which have a thicker and stronger elastomeric shell and a more cohesive gel, will further extend the advantages of the third-generation implants.

ACKNOWLEDGEMENTS: This research was funded by a Medical Research Council of Canada University Industry Grant and by an Outcome Grant from the Canadian Society of Plastic Surgeons. 


\section{REFERENCES}

1. de Camara DL, Sheridan JM, Kammer BA. Rupture and aging of silicone gel breast implants. Plast Reconstr Surg 1993;91:828-34.

2. Peters WJ, Keystone E, Smith DC. Factors affecting the rupture of silicone-gel breast implants. Ann Plast Surg 1994;32:449-51.

3. Collis N, Sharpe DT. Silicone gel-filled breast implants integrity: A retrospective review of 478 consecutively explanted implants. Plast Reconstr Surg 2000;105:1979-85.

4. Peters WJ, Smith DC, Lugowski S. Failure properties of 352 explanted silicone-gel breast implants. Can J Plast Surg 1996;4:55-8.

5. Robinson OG, Bradley EL, Wilson DS. Analysis of explanted silicone implants: A report of 300 patients. Ann Plast Surg 1995;34:1-7.

6. Peters WJ, Smith DC, Fornasier V, et al. An outcome analysis of 100 women after explantation of silicone gel breast implants. Ann Plast Surg 1997;39:9-19.

7. Peters WJ, Pritzker K, Smith DC, et al. Capsular calcification associated with silicone breast implants: incidence, determinants and characterization. Ann Plast Surg 1998;41:348-60.

8. Peters WJ, Smith D, Lugowski S. All silicone gel breast implants were not created equal. Ann Plast Surg 1999;43:97-9.

9. Feng LJ, Amini B. Analysis of risk factors associated with rupture of silicone gel breast implants. Plast Reconstr Surg 1999; 104-955-63.

10. Peters WJ. Current status of breast implant survival properties and the management of the woman with silicone gel breast implants. Can J Plast Surg 2000;8:54-67.

11. Bondurant S, Ernster V, Herdman R, eds. Safety of Silicone Gel Breast Implants. Washington: Institute of Medicine, National Academy Press, 2000.

12. Peters WJ, Lugowski S, Pritzker KPH, Holmyard D. Calcification properties of saline-filled breast implants. Plast Reconstr Surg 2001;107:356-63. 